\title{
Circularly Polarized Suspended Patch Antenna Fed by Modified L-Probe for UHF RFID Reader
}

\author{
Kok Suen CHENG ${ }^{1}$, Eng-Hock LIM ${ }^{1}$, Yeong-Nan PHUA ${ }^{2}$ \\ ${ }^{1}$ Dept. of Electrical and Electronic Engineering, Universiti Tunku Abdul Rahman, Jalan Sungai Long, Bandar Sungai \\ Long, Cheras 43000, Selangor, Malaysia \\ ${ }^{2}$ Dept. of Mechatronics and Biomedical Engineering, Universiti Tunku Abdul Rahman, Jalan Sungai Long, Bandar Sungai \\ Long, Cheras 43000, Selangor, Malaysia
}

ventus1994@yahoo.com,limeh@utar.edu.my,phuayn@utar.edu.my

Submitted September 4, 2016 / Accepted June 7, 2017

\begin{abstract}
Two reader antennas, which are designed using the L-probe-fed suspended patch, are designed for the UHF band. To generate circular polarization, the Lshaped probe is modified by including an extra bend to provide one more degree of tuning freedom to the reflection coefficient without affecting the axial-ratio performance much. The proposed single-element reader antenna is able to achieve a CP bandwidth of $5.5 \%(890 \mathrm{MHz}$ to $940 \mathrm{MHz}$ ) and a maximum antenna gain of $9.7 \mathrm{dBi}$. When designed into a $2 \times 2$ array, the proposed reader antenna is able to produce CP bandwidth of $5.3 \%(910 \mathrm{MHz}$ to $960 \mathrm{MHz}$ ) with an antenna gain of $14.7 \mathrm{dBi}$. The read ranges of the proposed antenna and its array are $6.3 \mathrm{~m}$ and $10.9 \mathrm{~m}$, respectively.
\end{abstract}

\section{Keywords}

UHF reader antenna, L-probe-fed patch, circularly polarized reader antenna

\section{Introduction}

Radio-frequency identification (RFID) is an emerging technology that uses electromagnetic waves to extract information stored in a tag placed on an object. It is able to offer long reading range and multiple detections at the same time. As of now, RFID has been successfully implemented in property management, public transportation, and livestock identification [1]. The frequency range of $860 \mathrm{MHz}$ to $960 \mathrm{MHz}$, also known as the ultra-high frequency (UHF) band, is of particular interest as the wireless systems working in this frequency range is promising a higher data transfer rate. The regulated UHF RFID spectrum is $902 \mathrm{MHz}$ to $928 \mathrm{MHz}$ for the United States, $919 \mathrm{MHz}-923 \mathrm{MHz}$ for Malaysia, $952 \mathrm{MHz}-956.4 \mathrm{MHz}$ for Japan, and $866 \mathrm{MHz}-869 \mathrm{MHz}$ for Europe and others.

It is very desirable for a UHF RFID reader antenna to have wide bandwidth and good circular polarization (CP) so that the tag will not be affected by its orientation. One of the most common ways to achieve circular polarization is truncating the microstrip patch resonator. With the use of a simple truncated square patch, the design in [2] is able to achieve a $3-\mathrm{dB}$ axial ratio (AR) bandwidth of $2.4 \%$. Other techniques are also combined with the truncated patch with the aim of improving its AR bandwidth. Some of these techniques include using meandered strips [3], [4], loading slots into the patch [5], [6], and using stacked element [7, 8, 9]. In [9], a stacked patch antenna which consists of a parasitic patch, a radiating patch, and a microstrip line is proposed for wide impedance and AR bandwidths. Offset can also be introduced to the orientation of the feeding probe to generate two orthogonal electric fields that are $90^{\circ}$ out-of-phase. This technique is also used in [10-12], where the excitation probe is displaced along the diagonal line joining the two opposite corners of a patch radiator.

The application of the L-shaped probe for exciting a linearly polarized patch antenna was first demonstrated by Luk et al. in 1998 [13], achieving an impedance bandwidth of $36 \%$. Later, many researchers have successfully deployed the L-shaped probe for designing various CP antennas [14] and some of them are for the UHF RFID purposes. In [15], an arc-shaped L probe was used to feed a suspended circular patch with multiple slots to achieve a CP bandwidth covering $800 \mathrm{MHz}-1000 \mathrm{MHz}$. Although this design has large bandwidth, involvement of multiple slots may complicate the fabrication process. An L-shaped probe was deployed for exciting two slot-loaded circular patches in [16]. In this case, the two patches are stacked for achieving a CP bandwidth of $14.2 \%$. The only shortcoming here is that it requires the use of double-layer structure, which may increase the manufacturing costs. Radiating patches in other shapes are incorporated with the L probe for designing CP reader antennas in [17], [18]. A singlelayered triangular patch with a notch is presented in [17]. While in [18] a combination of the triangular and semicircular patches is proposed for generating CP operation. The impedance bandwidths of the two designs are $25.4 \%$ and $19.9 \%$, respectively, and the corresponding CP bandwidths are about $3.0 \%$ and $4.3 \%$. The L-probe was also used to design dual-polarized [19] and differential antennas [20]. 
In this paper, a novel and simple modified L-shaped probe feed, which consists of three wire sections, is introduced to excite an un-truncated rectangular patch for designing reader antenna for the UHF band in Malaysia. By using the newly modified L-probe-fed patch as the unit element, a $2 \times 2$ array antenna is also designed to achieve a higher antenna gain. For the antenna array, a Wilkinson power divider is used for splitting the input power into four channels for feeding the L-probe-fed patches. Both the single-element antenna and antenna array are simulated using the CST Microwave Studio. Prototypes were built and the measured results were compared with the simulated results. Detailed parametric analysis has been conducted to investigate the performance of the proposed antenna.

\section{Antenna and Array Configurations}

The configuration of the single-element L-probe-fed patch antenna is discussed first. It consists of three parts: ground plane, folded L-shaped probe, and radiating patch, as shown in Fig. 1. Both of the ground plane $\left(G_{x}, G_{y}\right)$ and the radiating patch $(W, L)$ are made up of rectangular aluminum plates, while the probe is built using a copper wire with radius $r_{1}$. Here, the excitation probe is modified from the conventional L-probe by folding an extra bend. With reference to Fig. 1, the feeding probe consists of 3 wire sections: the vertical wire section with length of $L_{\mathrm{v}}$ is pointing in the $z$ direction, the horizontal wire section with length $L_{\mathrm{h} 2}$ is directing in the $y$ direction, and the interconnecting wire with length $L_{\mathrm{h} 1}$ is in the $x$ direction. The Lshaped probe is excited using an SMA connecter, which is bolted to the ground plane with an offset of $(\Delta x, \Delta y)$ along the diagonal line joining the two opposite vertices. Such offset is essential for generating circular polarization. The radiating patch is positioned at a height $H$ from the ground plane using foams $\left(\varepsilon_{\mathrm{r}} \sim 1\right)$. The optimized parameter values are shown in Tab. 1, and the prototype of the optimized antenna is shown in Fig. 2.

Next, a $2 \times 2$ antenna array is designed using the single-element antenna. It consists of a Wilkinson power divider printed on a FR-4 substrate with thickness of $1.5 \mathrm{~mm}$, with a copper ground plane underneath the substrate. The four L-probes and the patches are placed on top of the power dividing network as shown in Fig. 3. The power dividing network is made up of multiple $50-\Omega$ (with line width of $2.87 \mathrm{~mm}$ ) and $70.7-\Omega$ (with line width of $1.51 \mathrm{~mm}$ ) strip lines, as well as a few matching resistors, so that good impedance matching can be achieved in all the five ports. An SMA connector is soldered to the $50 \Omega$ strip line, which has a small section of matching stub $(24 \mathrm{~mm})$ as input port.

When expanded into array, the length $(L)$ of the patches is slightly changed to $108 \mathrm{~mm}$ for achieving better performance in impedance matching and $\mathrm{CP}$ bandwidth. Figure 4 is a photograph showing the profile view of the fabricated $2 \times 2$ antenna prototype for the UHF reader.

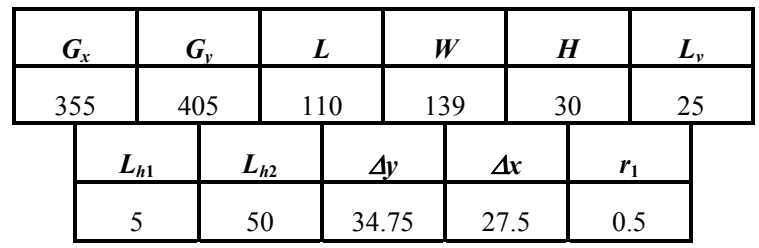

Tab. 1. Optimized parametric values for the single-element L-probe-fed patch antenna (in $\mathrm{mm}$ ).

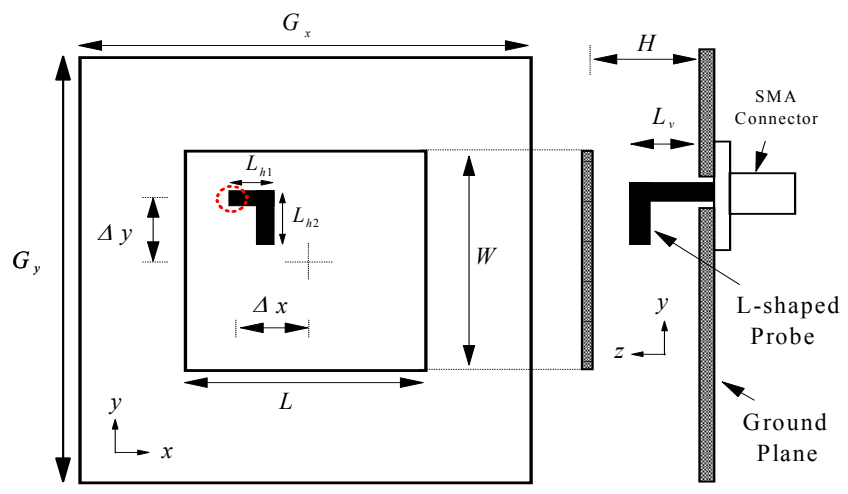

(a)

(b)

Fig. 1. Schematics of the proposed single-element antenna. a) Top view. (b) Side view.

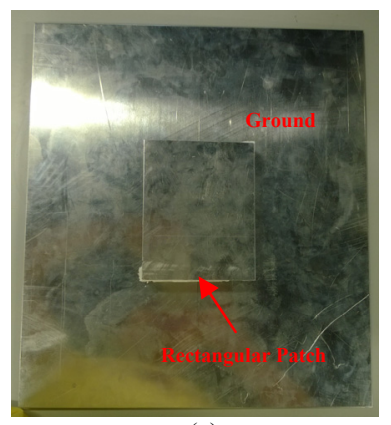

(a)

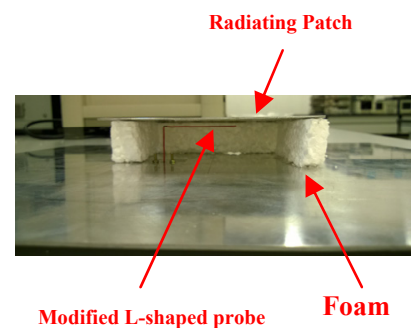

(b)
Fig. 2. Prototype of the single-element circularly polarized antenna. (a) Top view. (b) Side view.

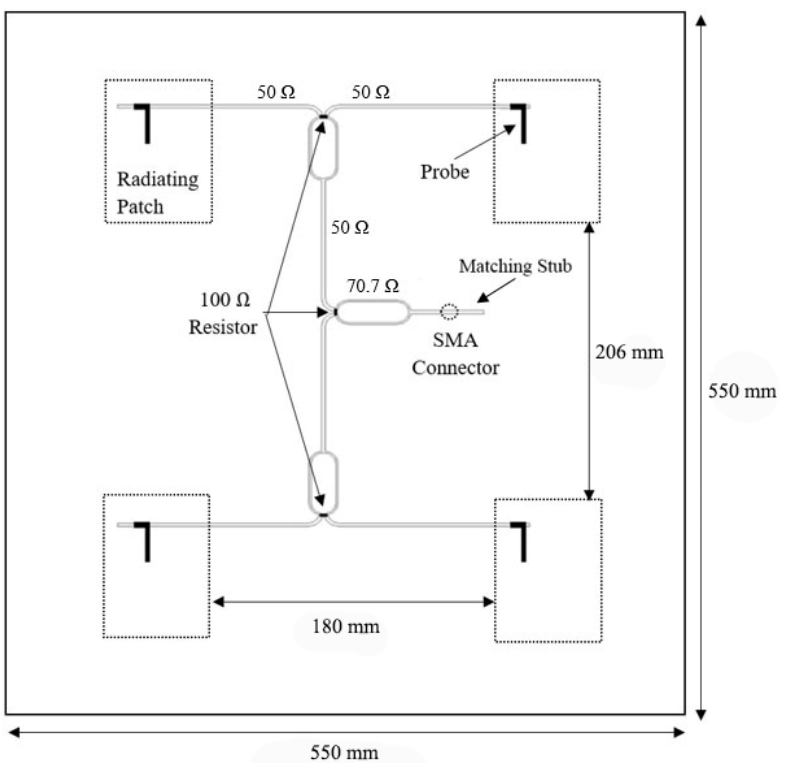

Fig. 3. Configuration of the $2 \times 2$ antenna array. 


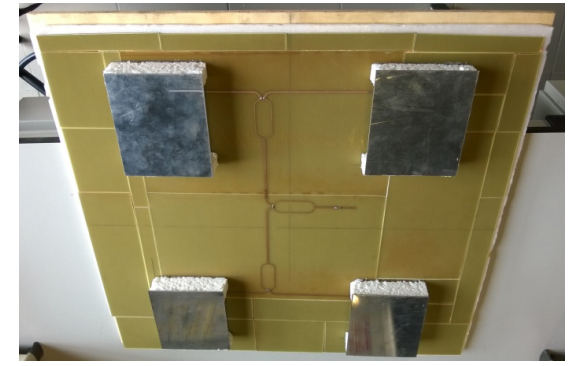

Fig. 4. Profile view of the fabricated $2 \times 2$ array prototype.

\section{Results and Discussion}

The reflection coefficient is measured using an R\&S ${ }^{\circledR}$ ZVB8 Vector Network Analyzer (VNA), and the read range of the proposed antenna is measured by connecting the antenna to a commercially available UHF reader $\mathrm{Mi}-1801 \mathrm{~B}$, where the power of the reader is set to be $30 \mathrm{dBm}$. For assessing the read range of the reader antenna, an RAPITA ${ }^{\circledR}$ UHF RFID tag is stuck on a piece of foam block secured on a stand as depicted in Fig. 5.

Figure 6(a) shows the simulated and measured reflection coefficients of the proposed single-element antenna. In general, the measured result is in good agreement with the simulated one. From the measured reflection curves, it can be seen that there are two resonance dips, one at $800 \mathrm{MHz}$ (simulation: $800 \mathrm{MHz}$ ) and the other one at $880 \mathrm{MHz}$ (simulation: $905 \mathrm{MHz}$ ). The prototype has achieved a measured impedance bandwidth from $760 \mathrm{MHz}$ to $990 \mathrm{MHz}(26.3 \%)$, which is slightly smaller than the simulated one of $760 \mathrm{MHz}$ to $1050 \mathrm{MHz}(31.9 \%)$. In the axial ratio measurement, the proposed antenna is set up as the transmitting antenna while an R\&S ${ }^{\circledR} H E 300 C E$ Active Directional Antenna is deployed as the receiving antenna in the far-field region. The power received by the directional antenna is measured at two orthogonal orientations with respect to the transmitting antenna, and the corresponding axial ratio is then derived by taking the differences between the two received powers. Figure 6(b) shows the simulated and measured axial ratios of the proposed antenna. The proposed single-element antenna is able to achieve a 3-dB AR bandwidth of $5.5 \%(890 \mathrm{MHz}$ to $940 \mathrm{MHz}$ ) and the lowest axial ratio occurs at $910 \mathrm{MHz}$ with a magnitude of $1.6 \mathrm{~dB}$. Obviously, the $\mathrm{CP}$ operation of this antenna is limited by its AR performance. For this case, the frequency range is sufficient to cover the UHF RFID bandwidth $(919 \mathrm{MHz}-923 \mathrm{MHz})$ of Malaysia. The electric field distributions of the single-element L-probefed patch antenna are shown in Fig. 7. Electric fields in the cavity region between the patch and its ground show that the displacement of the L-probe at this location has enabled the excitation of the degenerate $\mathrm{TM}^{\mathrm{z}}{ }_{010}$ modes at $800 \mathrm{MHz}$ (shown in Fig. 7(a)) and $905 \mathrm{MHz}$ (shown in Fig. 7(b)), respectively. The combination of the two modes has made the $\mathrm{CP}$ operation possible in this case.

The antenna gain and radiation patterns of the singleelement antenna are then measured. With reference to

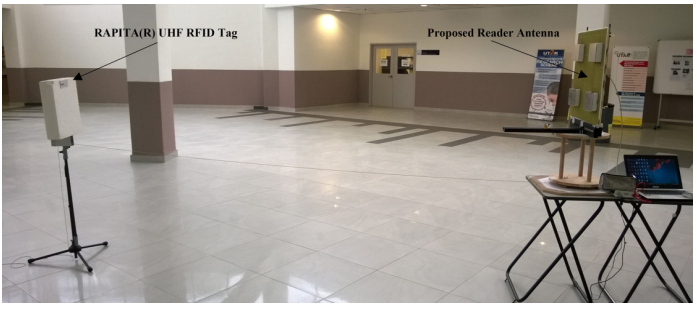

Fig. 5. Experimental setup for measuring the read range of the reader antenna.

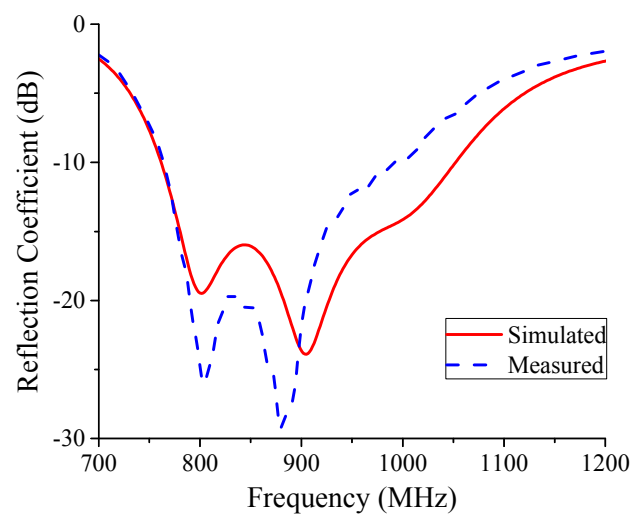

(a)

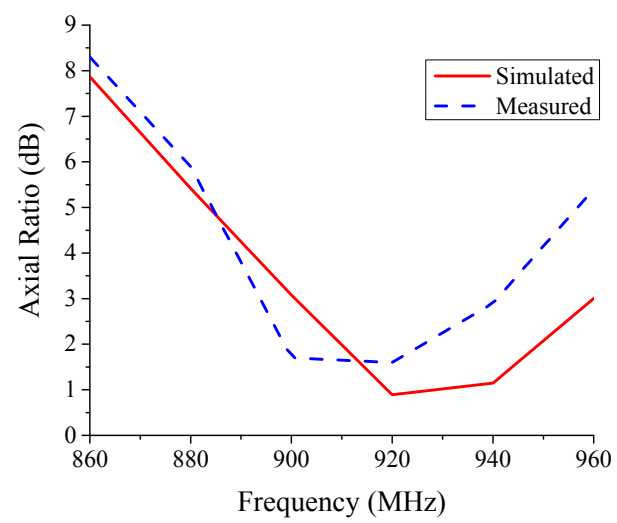

(b)

Fig. 6. Simulated and measured (a) reflection coefficients and (b) axial ratios of the single-element antenna.

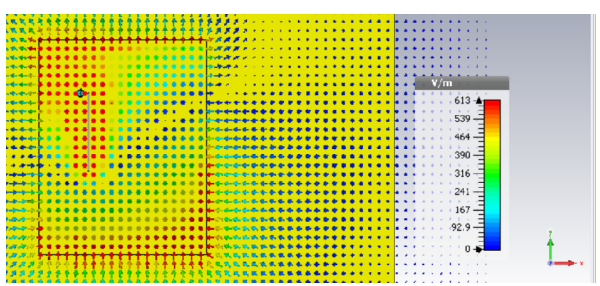

(a)

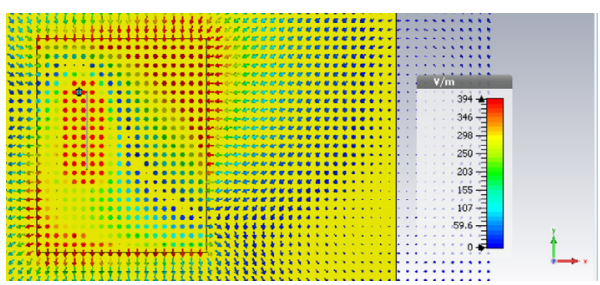

(b)

Fig. 7. Electric field distributions of the L-probe-fed patch at (a) $800 \mathrm{MHz}$, (b) $905 \mathrm{MHz}$. 


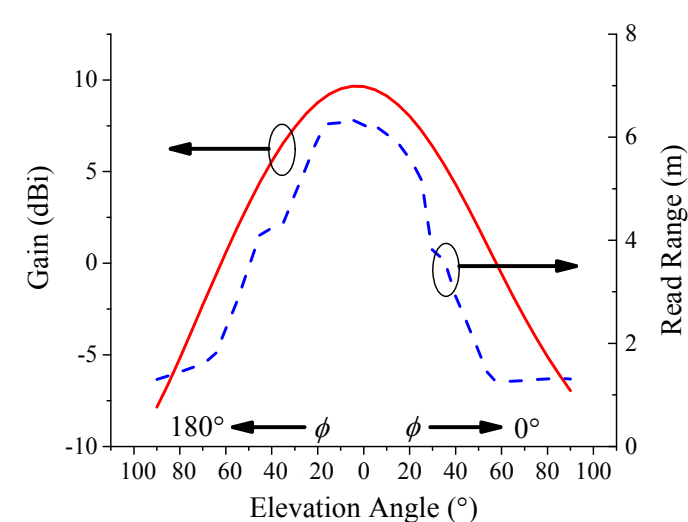

(a)

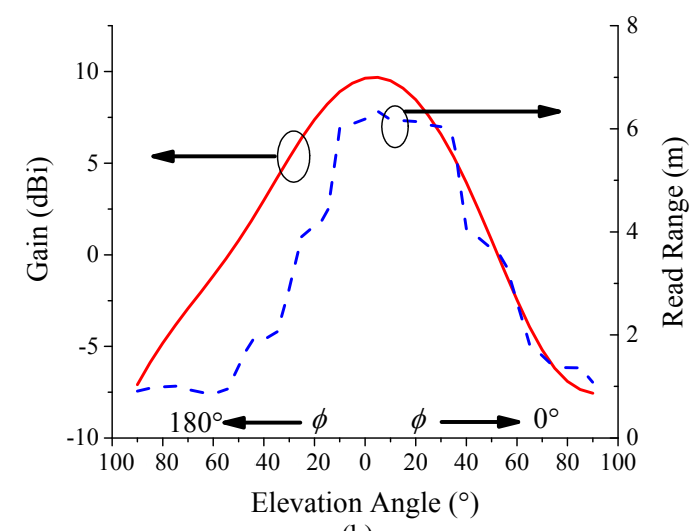

(b)

Fig. 8. Simulated radiation pattern and measured read range in the (a) $x-z$ plane and (b) $y-z$ plane, at $920 \mathrm{MHz}$.

Figs. 8(a) and (b), the simulated antenna gains and the measured read ranges of the proposed single-element antenna are presented at $920 \mathrm{MHz}$ in the $x-z$ and $y-z$ planes as a function of elevation angle $\theta$, respectively. The simulated peak gain is $9.7 \mathrm{dBi}$ with a broadside radiation pattern. It corresponds to a read range of $6.3 \mathrm{~m}$. Both of the antenna gain and read range decrease as the elevation angle is increased (both $x-z$ and $y-z$ planes). At $90^{\circ}$ and $-90^{\circ}$, the read range is $1.3 \mathrm{~m}$.

Figure 9(a) depicts the simulated and measured reflection coefficients for the proposed $2 \times 2$ antenna array. The simulated result shows that the impedance bandwidth ranges from $890 \mathrm{MHz}$ to $960 \mathrm{MHz}$ and it is limited by the frequency response of the Wilkinson power divider. Figure 9(b) shows the simulated and measured axial ratios of the proposed antenna. As can be seen, the measured 3-dB AR bandwidth is $5.4 \%$, covering the frequency range of $910 \mathrm{MHz}-960 \mathrm{MHz}$, showing reasonable agreement with the simulated results $(5.35 \%, 895 \mathrm{MHz}-945 \mathrm{MHz})$. The discrepancy in resonance frequency can be due to manufacturing tolerances. Figures 10 (a) and (b) show the simulated antenna gain and measured read range of the proposed antenna array in the $x-z$ plane and $y-z$ plane at $920 \mathrm{MHz}$. The simulated peak gain is in the boresight $(\theta=$ $0^{\circ}$ ) direction, giving a maximum gain of $14.7 \mathrm{dBi}$. This trend is reflected in the measured read range, which maximizes at $10.9 \mathrm{~m}$ in this direction. The read range decreases until a minimum distance of about $1 \mathrm{~m}$ at $\theta=35^{\circ}$ (both $x-z$ and $y$-z planes).

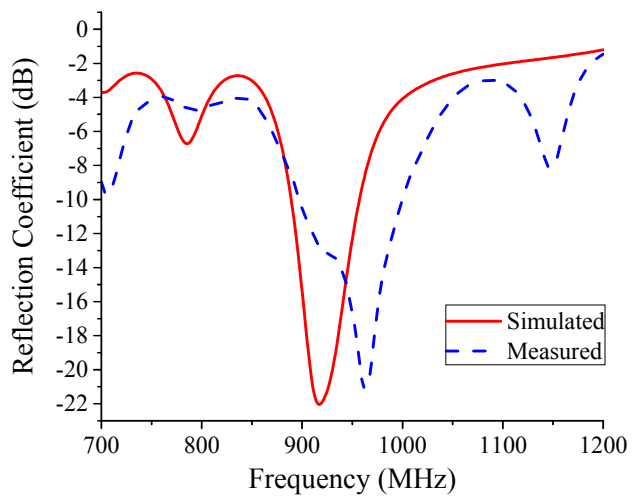

(a)

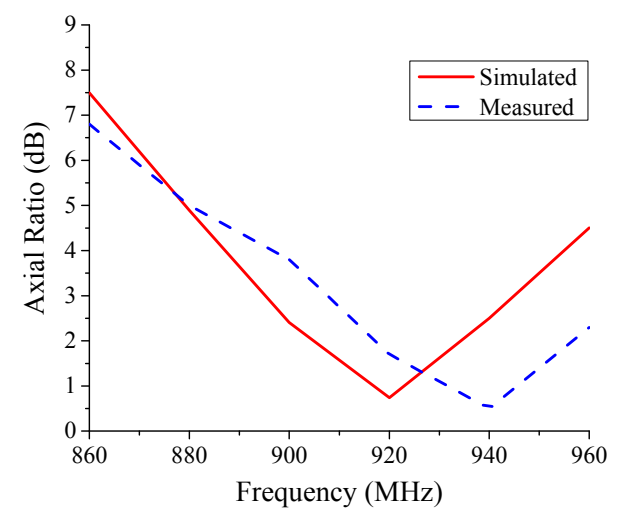

(b)

Fig. 9. Simulated and measured (a) reflection coefficients and (b) axial ratios of the proposed antenna array.

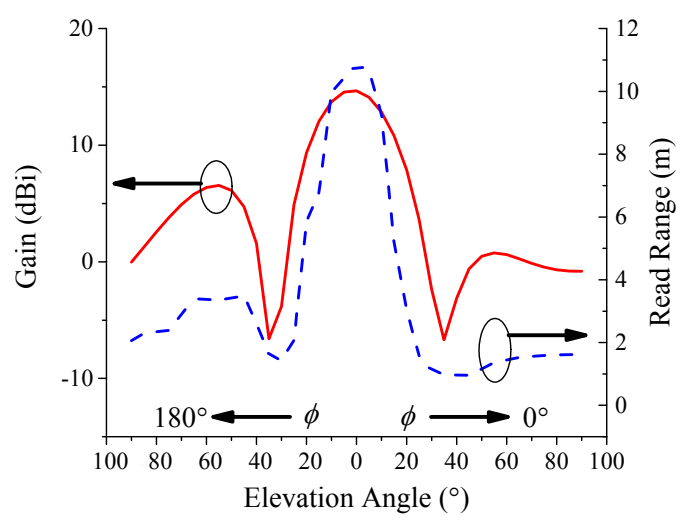

(a)

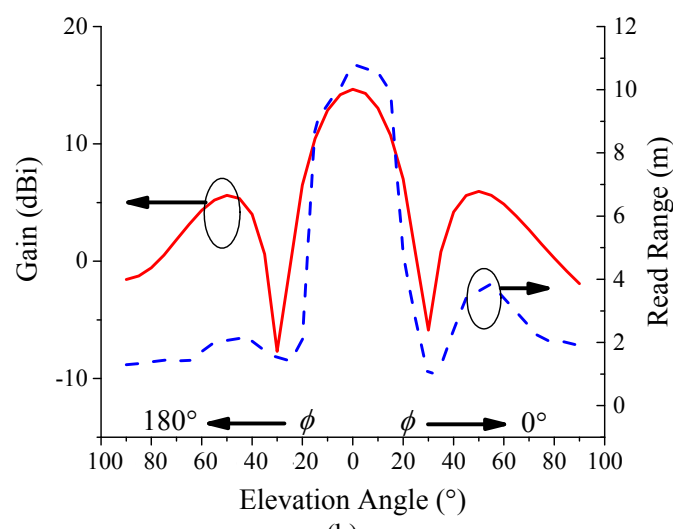

(b)

Fig. 10. Simulated antenna gain and measured read range in the (a) $x-z$ plane and (b) $y-z$ plane of the $2 \times 2$ antenna at $920 \mathrm{MHz}$. 
The proposed single-element antenna (with bend and offset) is first compared to a similar suspended patch antenna centrally fed by a traditional L-probe which does not have any bend. Simulations show that only the modified L-probe with an offset is able to achieve circular polarization but not for the centrally fed probe. Then, the traditional L-probe is simply offset to the same excitation location $(\Delta x, \Delta y)$ like that for the proposed antenna. In this case, the antenna performances such as reflection coefficients, ARs and gains for the cases with and without a bend are almost similar. This holds for both the single-element and array. It will be shown in the parametric analysis that the extra bend introduced in the probe gives one more degree of freedom for tuning the impedance matching of the antennas.

\section{Parametric Analysis}

In order to gain further insight into the design parameters of the proposed single-element antenna, a detailed parametric analysis has been performed to visualize their effects on the reflection coefficient and axial ratio. First, the length of the patch, $l$ is studied. Figure 11(a) shows the reflection coefficients for three different lengths $(l=$ $100 \mathrm{~mm}, 110 \mathrm{~mm}$ and $120 \mathrm{~mm}$ ). The first resonant dip at $800 \mathrm{MHz}$ is not affected by the change in $l$. However, the following resonant dip has shifted to a higher frequency when the length is increased. At $l=120 \mathrm{~mm}$, the second resonance dip shifts to $960 \mathrm{MHz}$ with a good matching level of $-36 \mathrm{~dB}$. Figure 11(b) shows the effects of the length on the axial ratio. For the patch length of $120 \mathrm{~mm}$, the antenna doesn't have good CP characteristics as its axial ratio is greater than $3-\mathrm{dB}$ across the entire UHF frequency range. As for $l=100 \mathrm{~mm}$, the trend shows that it may have the possibility of exhibiting $\mathrm{CP}$ at a higher frequency, but since the purpose is to use the antenna as a UHF RFID reader, the result in this frequency range will not be discussed further.

Next, the width of the patch $w$ is varied and the effects are investigated. Figure 12(a) shows the reflection coefficients for different values of $w$. When $w$ is increased, both of the resonances shift to lower frequencies. For $w=$ $129 \mathrm{~mm}$, the passband is $800 \mathrm{MHz}-1080 \mathrm{MHz}$. For $w=$ $149 \mathrm{~mm}$, the impedance bandwidth has reduced to the range of $737 \mathrm{MHz}-810 \mathrm{MHz}$, which is out of the UHF range. The similar trend is also seen in the axial ratio, as shown in Fig. 12(b). As $w$ increases, the operational CP bandwidth shifts to lower frequencies. For the case of $w=$ $129 \mathrm{~mm}$, no AR bandwidth is available within the range of interest. While for $149 \mathrm{~mm}$, the AR bandwidth is covering $890 \mathrm{MHz}-935 \mathrm{MHz}$, which corresponds to $4.9 \%$ of bandwidth.

Effects of the height of the patch on the reflection coefficient and axial ratio are studied as well. Figure 13(a) shows how the reflection coefficient is changing with different heights $(H=20 \mathrm{~mm}, 30 \mathrm{~mm}$ and $40 \mathrm{~mm})$. The height of the patch relative to the ground plane is a crucial param-

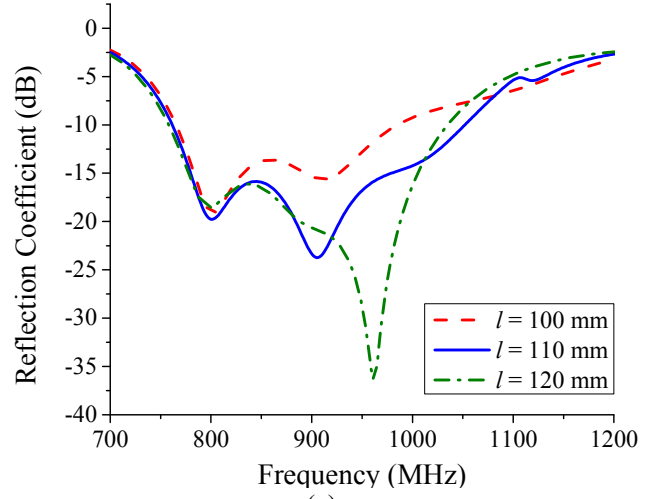

(a)

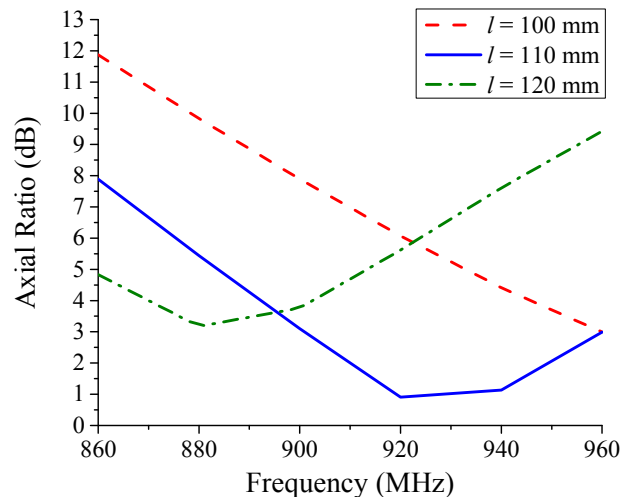

(b)

Fig. 11. Effects of the patch length $l$ on the (a) reflection coefficient and (b) axial ratio of the proposed singleelement antenna.

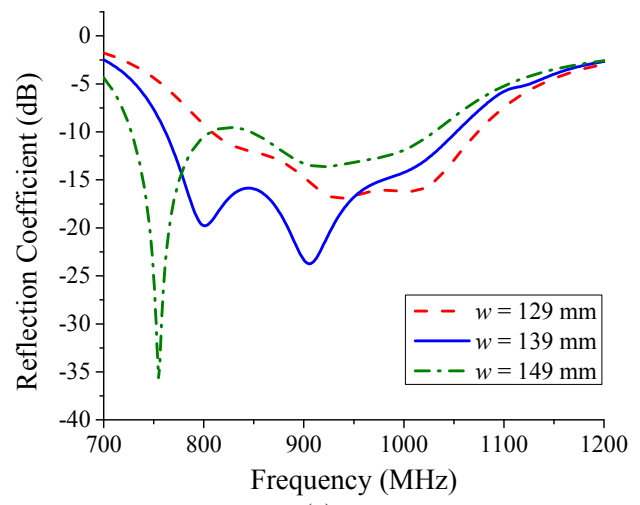

(a)

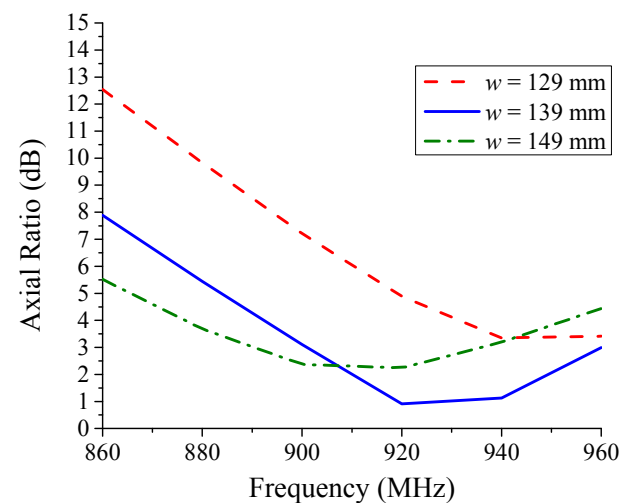

(b)

Fig. 12. Effects of the patch width $w$ on the (a) reflection coefficient and (b) axial ratio of the proposed singleelement antenna. 


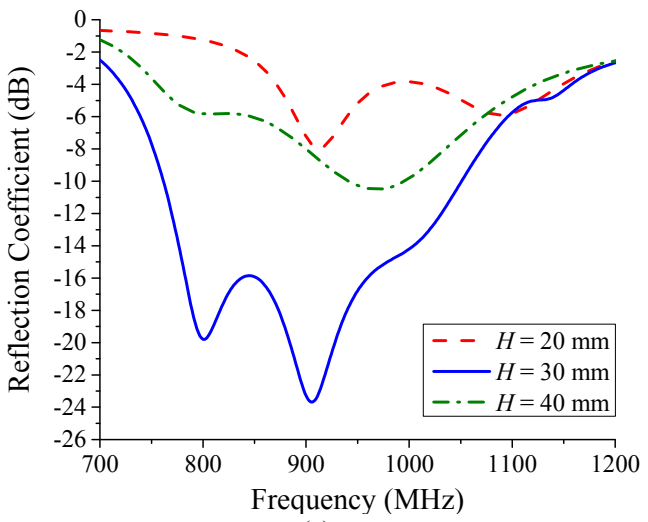

(a)

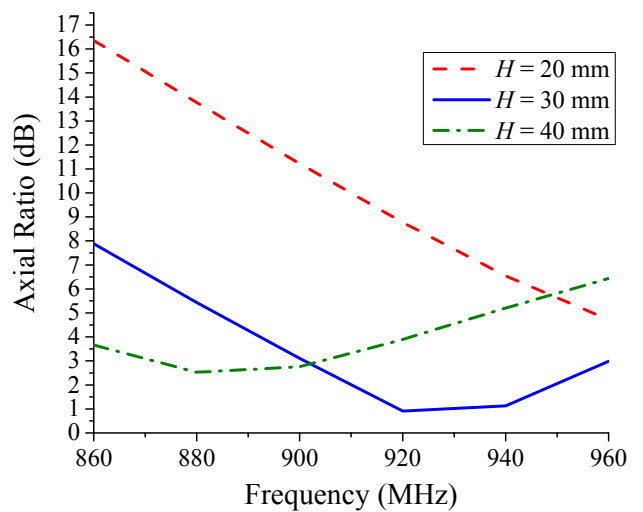

(b)

Fig. 13. Effects of the height of the patch $H$ on the (a) reflection coefficient and (b) axial ratio of the proposed single-element antenna.

eter as only slight difference of $10 \mathrm{~mm}$ can totally detune the antenna performance. Even though the two resonant dips are still visible, their reflection magnitude jeopardizes as $H$ is changed from the dominant value. As can be seen in Fig. 13(b), the AR bandwidth shifts lower as the height is increased. When the height of the patch is made $20 \mathrm{~mm}$, the axial ratio performance deteriorates, making it not suitable for RFID usage. At $H=40 \mathrm{~mm}$, a small working $\mathrm{CP}$ range of $870 \mathrm{MHz}-905 \mathrm{MHz}$ is observed. However, when the reflection coefficient is taken into consideration, this configuration is not a viable one.

Now the parameters related to the modified L-shaped probe are investigated. First, the vertical length of the probe $L_{\mathrm{v}}$ is varied from $20 \mathrm{~mm}$ to $30 \mathrm{~mm}$ with $5 \mathrm{~mm}$ increment. As can be seen from Fig. 14(a), $L_{\mathrm{v}}$ is another parameter that has significant effect on the reflection characteristics. A small change of $5 \mathrm{~mm}$ can worsen the performance of the antenna by a lot. For $L_{\mathrm{v}}=20 \mathrm{~mm}$, there is still a resonance dip with magnitude smaller than $-10 \mathrm{~dB}$ at $1000 \mathrm{MHz}$, but the magnitude is only around $-11 \mathrm{~dB}$. When $L_{\mathrm{v}}$ is increased to the proposed length of $25 \mathrm{~mm}$, a very good resonance with large bandwidth can be achieved. However, slight increase of $5 \mathrm{~mm}$ to $30 \mathrm{~mm}$ can completely get the resonance detuned. The effects of the axial ratio are shown in Fig. 14(b). Varying $L_{\mathrm{v}}$ does not have significant effect on the axial ratio. Thus, $L_{\mathrm{v}}$ is an important parameter to tune the impedance matching without affecting the axial ratio much.

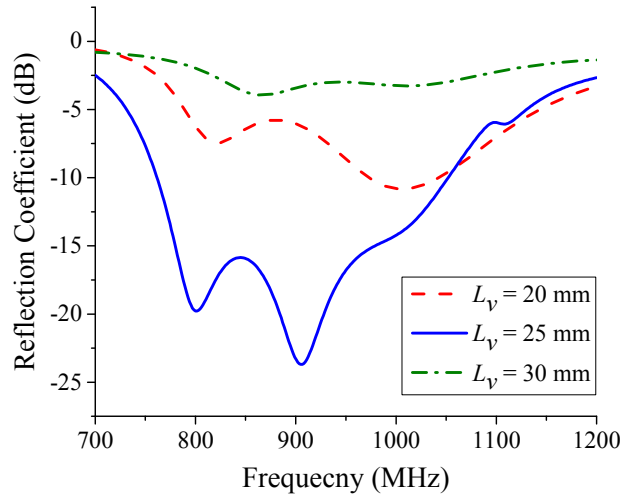

(a)

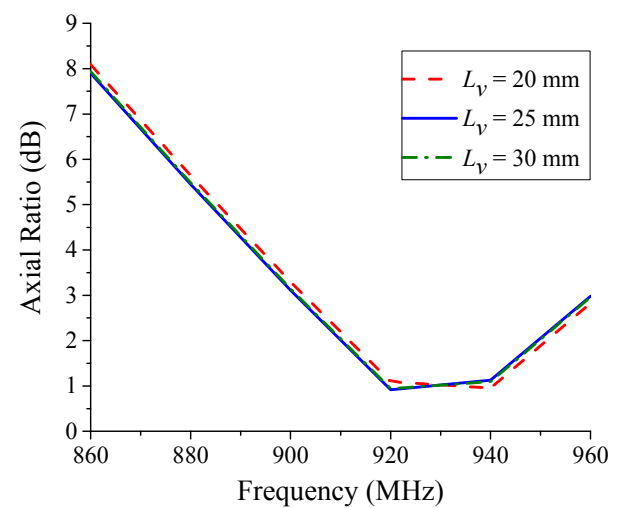

(b)

Fig. 14. Effects of the vertical length of the probe $L_{\mathrm{v}}$ on the (a) reflection coefficient and (b) axial ratio of the proposed single-element antenna.

Subsequently, the effects of the wire section $L_{\mathrm{h} 1}$ are studied for three different lengths $(2.5 \mathrm{~mm}, 5.0 \mathrm{~mm}$ and $7.5 \mathrm{~mm}$ ). The results are shown in Figs. 15(a) and (b). Changing $L_{\mathrm{h} 1}$ does not affect the resonant frequency of the lower resonance, but the magnitude can be significantly affected. As can be seen from Fig. 15(a), the magnitudes for the three different lengths are $-15 \mathrm{~dB},-20 \mathrm{~dB}$ and $-29 \mathrm{~dB}$, respectively. When $L_{\mathrm{h} 1}$ is increased, the impedance matching level of the two resonances improves. As for the higher resonance dip, both the resonant frequency and the magnitude are affected by the change in $L_{\mathrm{h} 1}$. It can be seen from Fig. 15(a) that increasing $L_{\mathrm{h} 1}$ causes the resonance to shift to lower frequencies. On the other hand, the AR passband is not affected by $L_{\mathrm{h} 1}$ much, as shown in Fig. 15(b). One noticeable difference is that better axial ratio $(\sim 0.5 \mathrm{~dB})$ is achievable at $920 \mathrm{MHz}$ when $L_{\mathrm{h} 1}$ is $7.5 \mathrm{~mm}$. Finally, the wire section $L_{\mathrm{h} 2}$ is varied from $40 \mathrm{~mm}$ to $60 \mathrm{~mm}$, and the effects on the reflection response are studied in Fig. 16(a). Again, both of the resonances fluctuate when $L_{\mathrm{h} 2}$ is varied. The axial ratio performance is not affected much by any change in $L_{\mathrm{h} 2}$ in this range.

Comparison between the proposed antenna and some of the traditional L-probe-fed reader antennas is shown in Tab. 2. The impedance bandwidth and the maximum gain achieved by the proposed antenna is the largest among the rest, whereby the larger gain can be associated with larger ground plane. However in terms of the AR bandwidth, this work shows a greater bandwidth when compared to [22] 


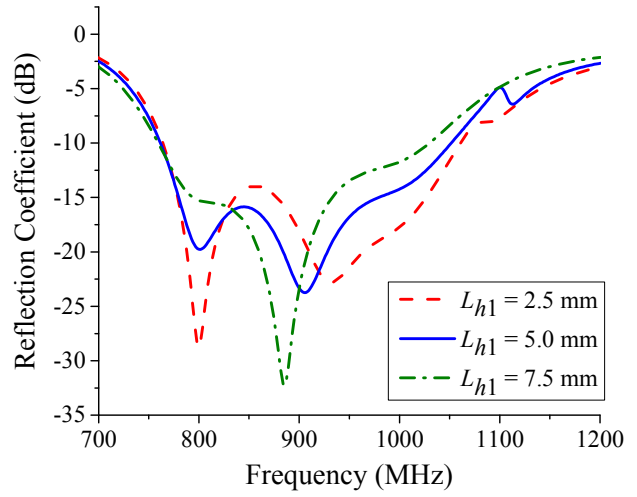

(a)

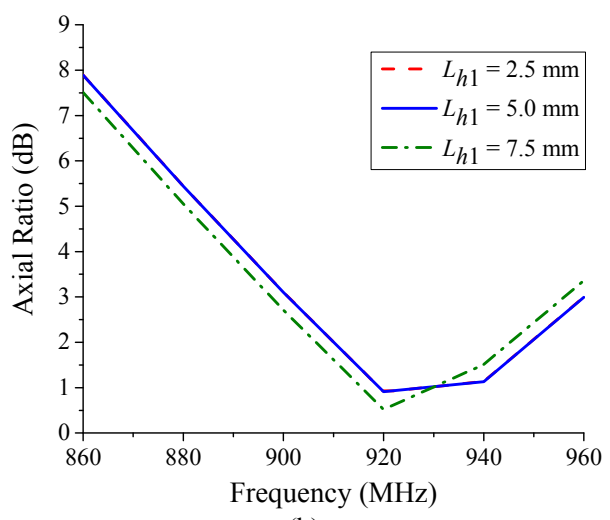

(b)

Fig. 15. Effects of the probe length $L_{\mathrm{h} 1}$ on the (a) reflection coefficient and (b) axial ratio of the proposed singleelement antenna.

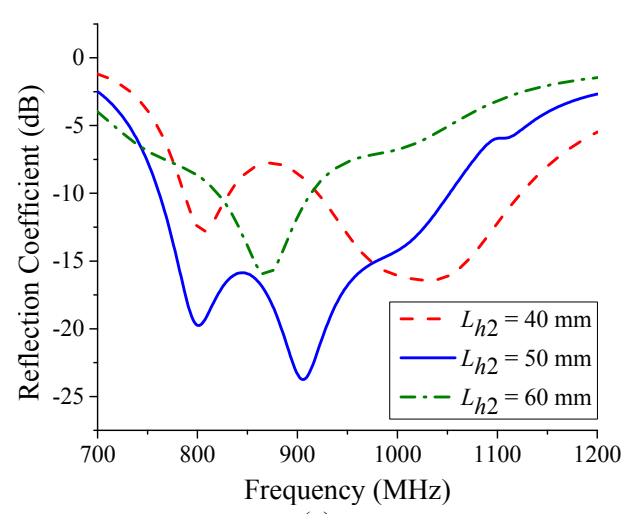

(a)

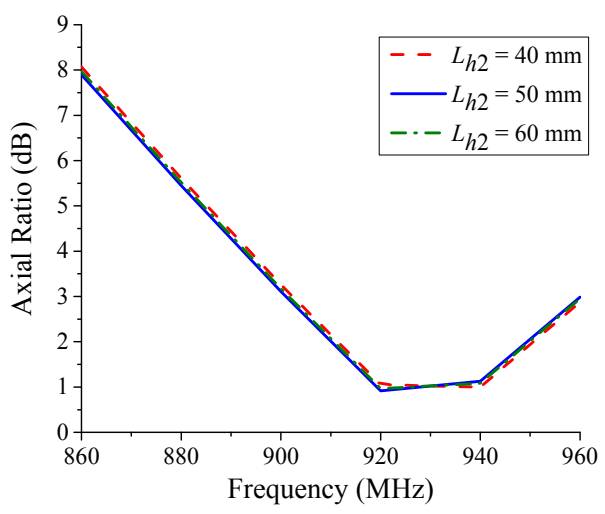

(b)

Fig. 16. Effects of the probe length $L_{\mathrm{h} 2}$ on the (a) reflection coefficient and (b) axial ratio of the proposed singleelement antenna.

\begin{tabular}{|c|c|c|c|c|}
\hline Antenna & $\begin{array}{c}\text { Impedance } \\
\text { Bandwidth } \\
(\mathrm{MHz}, \%)\end{array}$ & $\begin{array}{c}\text { AR } \\
\text { Bandwidth } \\
(\mathrm{MHz}, \%)\end{array}$ & $\begin{array}{c}\text { Maximum } \\
\text { Gain }(\mathrm{dBi})\end{array}$ & Size $\left(\mathrm{mm}^{3}\right)$ \\
\hline$[15]$ & $\begin{array}{c}800-1000, \\
22.2\end{array}$ & $\begin{array}{c}800-1000, \\
22.2\end{array}$ & 8.0 & $\begin{array}{c}250 \times 250 \\
\times 50\end{array}$ \\
\hline$[16]$ & $\begin{array}{c}823-966, \\
16\end{array}$ & $\begin{array}{c}837-963, \\
14.0\end{array}$ & 8.8 & $\begin{array}{c}200 \times 200 \\
\times 48\end{array}$ \\
\hline$[21]$ & $\begin{array}{c}857-950, \\
10.3\end{array}$ & $\begin{array}{c}878-945, \\
7.4\end{array}$ & 2.09 & $\begin{array}{c}120 \times 80 \\
\times 0.8\end{array}$ \\
\hline$[22]$ & $\begin{array}{c}908-941, \\
3.5\end{array}$ & $\begin{array}{c}922-928, \\
0.65\end{array}$ & 7.2 & $\begin{array}{c}150 \times 150 \\
\times 10.4\end{array}$ \\
\hline $\begin{array}{c}\text { This } \\
\text { work }\end{array}$ & $\begin{array}{c}760-990, \\
26.3\end{array}$ & $\begin{array}{c}890-940, \\
5.5\end{array}$ & 9.7 & $\begin{array}{c}355 \times 405 \\
\times 30\end{array}$ \\
\hline
\end{tabular}

Tab. 2. Comparison between the proposed antenna and some of the traditional L-probe-fed patch antennas.

but not [15], [16] and [21]. Even though this work has a smaller AR bandwidth, the advantage can be seen in terms of the simple design. In [15] and [16], the antenna configurations require multiple slots in the radiating patch, in addition to needing multiple stacked elements to achieve the desired characteristics. The monopole structure in [21] has very low antenna gain. The proposed antenna is simple and cost-effective as it only involves one ground plane, one probe, and one rectangular radiating patch without needing additional slots and stacking elements to achieve high antenna gain.

\section{Conclusion}

A modified L-shaped probe is explored as the feeder of the suspended rectangular patch for designing a circularly polarized UHF reader antenna. Here, the feeding probe is comprised by an L-shaped probe which has an extra bend section, and the probe is placed along the diagonal line of the rectangular patch for generating degenerate modes. The bend has provided one more degree of tuning freedom to the reflection coefficient without affecting the AR performance much. The proposed singleelement reader antenna and its array are able to generate AR bandwidth of $5.5 \%$ and $5.3 \%$, respectively. Testing on the RAPITA ${ }^{\circledR}$ UHF RFID tag with a power of $30 \mathrm{dBm}$, the proposed reader antenna has achieved a maximum read range of $6.3 \mathrm{~m}$ and the $2 \times 2$ array is able to reach $10.9 \mathrm{~m}$ in open space. Both of the proposed antennas can be used by the UHF readers in Malaysia. Good agreement has been found between the simulated and measured results.

\section{References}

[1] KARMAKAR, N. Handbook of Smart Antennas for RFID Systems. Hoboken (NJ, USA): Wiley, 2010. ISBN: 978-0-47038764-1

[2] LU, Y., CUI, H., SUN, X., XU, M., YIN, Y. A simple UHF RFID circularly-polarized reader antenna design. In 2011 IEEE Electrical Design of Advanced Packaging and Systems Symposium (EDAPS). 2011. DOI: 10.1109/EDAPS.2011.6213755

[3] WANG, Z., FANG, S., FU, S., MUJIE, F. Single-fed single-patch broadband circularly polarized antenna for UHF RFID reader 
applications. In 2010 2nd International Conference on Industrial and Information Systems. Dalian (China), 2010. DOI: 10.1109/INDUSIS.2010.5565908

[4] WANG, Z., FANG, S., FU, S., FU, S., JIA, S. Single-fed broadband circularly polarized stacked patch antenna with horizontally meandered strip for universal UHF RFID applications. IEEE Transactions on Microwave Theory and Techniques, 2011, vol. 59, no. 4, p. 1066-1073. DOI: 10.1109/TMTT.2011.2114010

[5] SIM, C., HSU, Y., YANG, G. Slits loaded circularly polarized universal UHF RFID reader antenna. Antennas and Wireless Propagation Letters, 2015, vol. 14, p. 827-830. DOI: 10.1109/LAWP.2014.2382557

[6] ANJU MARIA, VISHNUPRIYA, V., AJU JOHN, K. K., et al. Dual band circularly polarized truncated patch antenna for RFID reader and WiMAX applications. In The 2nd International Conference on Electronics and Communication Systems (ICECS). Coimbatore (India), 2015. DOI: 10.1109/ECS.2015.7124996

[7] WANG, B., HE, Z., LIU, H., OKUNO, Y., HE, S. A wideband circularly polarized antenna with Wilkinson feed network for worldwide UHF band RFID reader. In Progress In Electromagnetics Research Proceedings. Prague (Czech Republic), 2015. 4 p.

[8] NORZELI, S., ISMAIL, I., BUSU, M. Designing an UHF RFID reader antenna. In IEEE Symposium on Humanities, Science and Engineering Research. Kuala Lumpur (Malaysia), 2012. DOI: 10.1109/SHUSER.2012.6268894

[9] CHEN, Z. N., QING, X., CHUANG, H. L. A universal UHF RFID reader antenna. IEEE Transactions on Microwave Theory and Techniques, 2009, vol. 57, no. 5, p. 1275-1282. DOI: 10.1109/TMTT.2009.2017290

[10] BOO, Y., NASIMUDDIN, CHEN, Z., ALPHONES, A. Broadband circularly polarized microstrip antenna for RFID reader applications. In Asia Pacific Microwave Conference. Singapore, 2009, p. 625-628. DOI: 10.1109/APMC.2009.5384142

[11] KRUEKAEW, A., PHONGCHAROENPANICH, C. Linear/circular polarization switchable antenna for UHF RFID reader. In International Symposium on Intelligent Signal Processing and Communications Systems (ISPACS). Chiang Mai (Thailand), 2011, 4 p. DOI: $10.1109 /$ ISPACS.2011.6146207

[12] ViJitSUlakKANA, P., THAiWIROT, W., AKKARAEKTHALIN, P., CHAIMOOL, S., UHF RFID reader using slanted slot patch metasurface on microstrip patch antenna. In IEEE Conference on Antenna Measurements \& Applications (CAMA). Chiang Mai (Thailand), 2015, 3 p. DOI: 10.1109/CAMA.2015.7428134
[13] LUK, K. M., MAK, C. L., CHOW, Y. L., LEE, K. F. Broadband microstrip patch antenna. Electronics Letters, 1998, vol. 34, no. 15 , p. 1442 to 1443 . DOI: $10.1049 / \mathrm{el}: 19981009$

[14] LUK, K. M., LEE, K. F., LAI, H. W. Development of wideband Lprobe coupled patch antenna. The Applied Computational Electromagnetics Society (ACES) Journal, 2007, vol. 22, no. 1, p. $88-96$. ISSN: $1054-4887$

[15] XU, J. F., CHEN, Z. N., QING, X. M. A broadband circularly polarized antenna. In 2012 IEEE Asia-Pacific Conference on Antennas and Propagation. Singapore, 2012, 2 p. DOI: 10.1109/APCAP.2012.6333131

[16] CHEN, C., CHEN, B., SIM, C. Broadband circularly polarized stacked patch antenna for universal UHF RFID applications. IEICE Transactions on Communications, 2016, vol. E99, no. 1, p. 2-8. DOI: $10.1587 /$ transcom.2015ISI0001

[17] SIM, C. Y. D., HSU, Y. W. Circularly polarized equilateral triangle patch antenna for UHF RFID reader applications. In Loughborough Antennas \& Propagation Conference (LAPC). Loughborough (UK), 2013, p. 397-399. DOI: 10.1109/LAPC.2013.6711928

[18] YEH, C. H., CHEN, B. S., CHEN, C. C., SIM, C. Y. D. L-shaped probe feed patch antenna with circular polarization radiation for UHF RFID applications. In IEEE MTT-S 2015 International Microwave Workshop Series on RF and Wireless Technologies for Biomedical and Healthcare Applications (IMWS-BIO). Taipei (Taiwan), 2015, p. 214-215. DOI: 10.1109/IMWSBIO.2015.7303853

[19] WONG, H., LAU, K. L., LUK, K. M. Design of dual-polarized Lprobe patch antenna arrays with high isolation. IEEE Transactions on Antennas and Propagation, 2004, vol. 52, no. 1, p. 45-52. DOI: 10.1109/TAP.2003.822402

[20] GAO, L., WANG, K. X., LAI, H. W., SO, K. K., WONG, H., XUE, Q., ZHANG, X. Y. Microstrip patch antenna with differential L-probe fed for wideband application. In Cross Strait Quad-Regional Radio Science and Wireless Technology Conference. New Taipei City (Taiwan), 2012, p. 172-174. DOI: 10.1109/CSQRWC.2012.6295000

[21] CAO, R., YU, S. Circularly polarized monopole slot antenna for UHF RFID reader. Microwave and Optical Technology Letters, 2016, vol. 58, no. 5, p. 1102-1105. DOI: 10.1002/mop.29758

[22] HUANG, G. L., SIM, C. Y. D., LIN, C. W., GAO, M. J. Lowprofile UHF RFID reader antenna with $\mathrm{CP}$ radiation and coupled feeding technique. International Journal of $R F$ and Microwave Computer-Aided Engineering, 2016, vol. 26, no. 9, p. 819-828. DOI: $10.1002 / \mathrm{mmce} .21034$ 